\title{
A EDUCAÇÃO PELO LIVRO: uma análise do compêndio de pedagogia de Dario Vellozo (1907) ${ }^{1}$
}

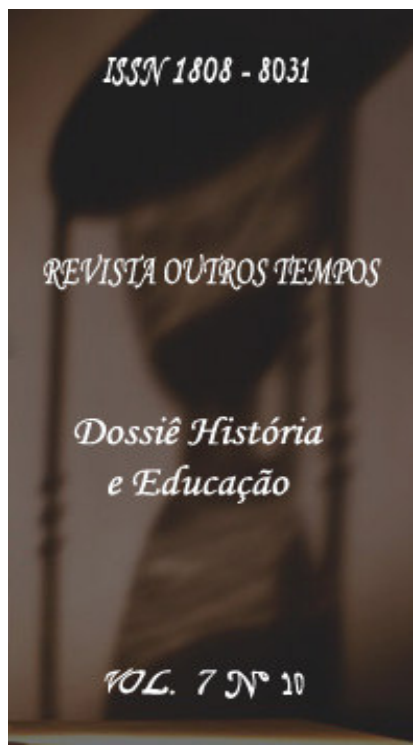

\author{
Ernando Brito Gonçalves Junior \\ Mestrando em Educação pela Universidade Federal do Paraná \\ ernandobrito@yahoo.com.br
} História Intelectual, levando em consideração os elementos textuais e contextuais. Por fim, concluímos que Vellozo defendia que a formação do cidadão deveria ser fomentada pela ideia de formação do corpo e da mente, com base na ciência e em alguns ideais republicanos.

Palavras-chave: Dario Vellozo. Educação. História Intelectual.

Abstract: the present research has the objective to discuss the purpose of "full-time education" presented by Dario Vellozo, an important intellectual, writer and professor who lived in Paraná between 1885 and 1937. According to Vellozo through gym class, intellectual education, moral education, esthetics and civic education citizens would become apt to ingress and act in society. Our analysis uses as source Dario's textbook entitled Compêndio de Pedagogia (Compendium of Education) published in 1907. trying to understand how the author articulates his students formation ideas. Therefore in the present research we sought to make an analysis based in intellectual history, considering the textual and contextual elements Lastly, we conclude that Vellozo defended that citizen's formation should be promote by the idea of body and mind formation based in science and some republican ideas.

Keywords: Dario Vellozo. Education. Intellectual History.

\footnotetext{
${ }^{1}$ Artigo recebido em 15/8/2010 e aceito em 8/10/2010
} 
O final do século XIX e o início do século XX foram marcados por transformações em diversos âmbitos no Brasil. Essas mudanças interferiram de maneira substancial na sociedade brasileira, pois, além de modificarem o cenário político do país, questões culturais e sociais sofreram impactos devido às novas formas de pensamento e de projetos sociais. Nesse sentido, seguindo o exemplo dos grandes centros brasileiros, como São Paulo e Rio de Janeiro, o estado do Paraná também respirou esses ares de transformação. De acordo com Etelvina de Castro Trindade e Maria Luiza Andreazza (2001, p. 66), “[...] qualquer pessoa que chegasse às cidades paranaenses no período da Primeira República encontraria, em maior ou menor grau, alguns signos da então moderna tecnologia: telégrafo, telefone ou luz elétrica; depois automóveis e bondes".

Assim, o final do século XIX foi um cenário de muitas inovações em Curitiba. Ao mesmo tempo em que se fazia uma intensa propaganda das ideias que fomentavam a consolidação de uma sociedade dita moderna, pautada nos signos do progresso do século XIX, os poderes públicos promoviam constantes modificações no cenário urbano que se apresentava naquele momento. Era constantemente noticiado em jornais e revistas o surgimento de novas indústrias, de ideias educacionais e atuações da administração pública como referências inegáveis do progresso que uma parte da sociedade curitibana vinha tentando alcançar. A maioria dessas mudanças foi financiada pela "burguesia ervateira", que manifestava desejos de modernização, ideais de civilidade e sonhos do progresso, reflexo da influência do pensamento europeu (CORRÊA, 2006).

Nesse sentido, Amélia Siegel Corrêa aponta, em sua dissertação acerca da imprensa e política no Paraná, que as ideias de modernização:

[...] refletiam-se no desenvolvimento material da cidade, cada vez mais urbanizada, com alterações arquitetônicas, difusão da luz elétrica, bondes, calçadas, telégrafo. Obras como a Estrada da Graciosa, concluída em 1873, e a ferrovia, entregue em 1885, trouxeram, para a capital, vários engenheiros (CORRÊA, 2006, p. 31).

O projeto de expansão da capital paranaense foi desenvolvido pelo governo do estado, pautado em um discurso de modernidade e civilização. A higienização do centro da cidade, a expansão das redes de esgoto, o alargamento das praças, a arborização e os calçamentos das ruas foram algumas das prioridades desse governo (TRINDADE; ANDREAZZA, 2001).

Outras importantes mudanças no cenário curitibano tiveram profunda influência no cotidiano dos moradores, como alterações na arquitetura da cidade em prol do seu 
embelezamento, além da criação de espaços culturais e de lazer, como cinemas, cafés e clubes (TEDARDI, 2002).

Essa grande preocupação em ocasionar várias mudanças se deve principalmente à necessidade de o regime republicano se diferenciar do regime monárquico. Essas transformações tinham por objetivo construir um imaginário de que o novo regime político estava ligado às mudanças e avanços tecnológicos, enquanto a monarquia era constantemente relacionada, pelos republicanos, ao atraso social (CARVALHO, 1990).

Com esse discurso, eles pretendiam conquistar, nas palavras de José Murilo de Carvalho (1990), o "coração e a mente da população". Para tanto, foram criados, além dos símbolos, um panteão de heróis para legitimar o regime recém-instaurado.

Como se pode notar, no estado do Paraná e, mais especificamente, na cidade de Curitiba - que se constitui como recorte espacial de nossa pesquisa - o período de transição e consolidação da República foi marcado por grandes transformações, tanto no que tange ao âmbito do espaço geográfico da cidade como ao cenário das ideias que circulavam na capital paranaense.

Nesse contexto, a cidade de Curitiba estava preocupada com a sua urbanização, no entanto, em um processo de enriquecimento, pelo comércio da erva-mate. Era, sem dúvida, o polo econômico e cultural do Paraná. Impressiona a grande quantidade de livros, revistas e jornais que foram publicadas nesse período, os quais apresentavam uma grande diversidade de opiniões, tendências e ramificações políticas, literárias e filosóficas.

Em virtude de todo esse processo de transformação vivenciado em Curitiba, várias correntes de pensamento ganharam adeptos e começaram a se destacar no cenário intelectual curitibano. Entre elas, o Anarquismo ${ }^{2}$, movimento de defesa de ideias anticlericais ${ }^{3}$, liderado por Dario Vellozo, que travou uma intensa batalha contra os clérigos paranaenses; os Católicos ${ }^{4}$, que lutavam para manter o ensino religioso; e o Simbolismo ${ }^{5}$, movimento literário que também teve a participação de Dario Vellozo.

\footnotetext{
${ }^{2}$ Sobre o anarquismo, em Curitiba nos remetemos a VALENTE, Silza Maria Pazello. A presença rebelde na Cidade Sorriso: contribuição ao estudo anarquista em Curitiba (1890-1920). 1992. Dissertação (Mestrado em Educação) - Universidade Estadual de Campinas (UNICAMP), Campinas, 1992.

${ }^{3}$ Essa questão é bem discutida no livro de MARCHETTE, Tatiana Dantas. Corvo no galho das acácias: o movimento anticlerical em Curitiba (1896-1912). Curitiba: Aos Quatro Ventos, 1999.

${ }^{4}$ Para maiores informações sobre os projetos educacionais católicos, ver: CAMPOS, Nevio de. Laicato Católico: o papel dos intelectuais no processo de organização do projeto formativo da Igreja Católica no Paraná (1926-1938). 2002. Dissertação (Mestrado em Educação) - Universidade Federal do Paraná (UFPR), Curitiba, 2002.

${ }^{5}$ Movimento pode ser entendido, segundo D’Onofrio (2002, p. 405): “[...] como movimento estético. Surgiu na França e vigorou nas duas últimas décadas do século passado, na fase da belle époque, época da boemia de
} 
Essas correntes de pensamento tiveram um importante papel no cenário político e social da cidade, fazendo com que vários intelectuais divulgassem propostas e tentassem cooptar um número maior de adeptos para seus grupos e agremiações.

Assim, percebemos que essas transformações nas mais diversas searas sociais foram algumas das tintas que pintaram o cenário curitibano do final do século XIX e início do século XX. Podemos perceber que o cenário intelectual desse período foi uma aquarela de ideias, e que vários personagens ajudaram a pintar esse contexto.

Entre os vários nomes de personagens que se destacaram na época como intelectuais, no sentido exposto acima, utilizamos como foco de nossa pesquisa o carioca Dario Vellozo, que viveu no Paraná entre os anos de 1885 até 1937, e teve toda sua produção intelectual gestada nesse estado.

A escolha de Dario Vellozo se deve à sua importância no cenário intelectual paranaense. Vellozo foi profícuo poeta, tipógrafo e professor de História, fundou e teve participação na criação de várias revistas e jornais, foi um dos participantes da fundação do IHGPR (Instituto Histórico e Geográfico Paranaense) e criou o INP (Instituto NeoPitagórico). Além disso, ele via a educação como o principal caminho para transformar a sociedade, empenhando-se ao máximo pela instrução da população, fosse através de suas aulas nas escolas ou no Instituto Neo-Pitagórico, ou de seus textos para conduzir a uma nova forma de sociedade.

Dario Persiano de Castro Vellozo nasceu no Rio de Janeiro, em 26 de novembro de 1869, e mudou-se para Curitiba no ano de 1885, com 16 anos, na companhia de seu pai e irmão. Fez do estado do Paraná seu "lar" e "[...] defendeu, perante os novos traços da República, o lugar do estado no cenário nacional” (TEDARDI, 2002, p. 13).

Sua vida desde cedo esteve relacionada ao mundo da imprensa e da literatura. Em seu primeiro emprego, ainda no Rio de Janeiro, trabalhou como aprendiz de encadernador e, posteriormente, tipógrafo (BEGA, 2001). Essa mesma profissão foi exercida por ele no jornal mais antigo do Paraná, o Dezenove de Dezembro, pouco depois de sua chegada a Curitiba, Vellozo logo entrou em contato com diversos intelectuais e passou a integrar esse rico cenário que se configurava na cidade. Juntamente com outros pensadores do período - como Ermelino

Montmartre, chamados de 'poetas decadentes', tomados pela sensação do fin du siècle. Acusa a crise dos ideais do complexo cultural positivista e apresenta uma nova proposta estética, fundamentada em valores espirituais. [...] Voltando, de um certo modo, à estética romântica, o Simbolismo aperfeiçoa o gosto pelo mistério das coisas, na tentativa de captar a realidade secreta do universo, nesse, encontrando uma Alma e descobrindo a correspondência entre os diversos elementos da natureza, expressa artisticamente através da metáfora sinestésica: ideias aromáticas, flor canora, luz falante, cheiro das cores, etc.”. 
de Leão, Emiliano Pernetta, Júlio Pernetta, Silveira Neto, Romário Martins, entre outros -, fundou várias revistas, como O mosqueteiro (1886/87), A idéia (1889), Revista Azul (1893, voltada ao público feminino), Club Coritibano (1891/94), Cenáculo (1895/97), Jerusalém (1898/1902), A Esphynge (1899/1906), A Escola (1906/1910), Ramo de Acácia (1909/1912), Myrto e Acácia (1916/1920), Phythagoras (1920) e Luz de Krotona (1921).

Sua produção não se resumiu às revistas ou jornais: ele também escreveu várias obras. Cláudio Denipoti fez um estudo sobre a trajetória intelectual de Vellozo, mostrando-nos que esse autor possui uma grande produção literária, revelando-se um dos mais fecundos e importantes escritores do Paraná. Denipoti arrola um total de 27 livros publicados entre os anos de 1889 a 1920: Primeiros ensaios (contos, 1889), Ephemeras (versos, 1890), Esquifes (1896), Alma penitente (poema, 1897), Althair (conto, 1898), Esothericas (versos, 1900), 12 de outubro: ensino Cívico (1901), Teatro de Wagner (1901), Licções de História (1902), Derrocada ultramontana (1905), No solio do Amanhan (romance, 1905), Voltaire, polêmica e crítica (1905), Compêndio de Pedagogia (1907), Helicon (versos, 1908), Moral dos Jesuítas (1908), Templo Maçonico (1909), Pelos Aborígenes (em colaboração com Júlio Pernetta, 1911), Ramo de Ouro (1911), Rudel (poema, 1912), A Cabana Fellah (conto, 1915), Da Therapeutica Occulta (1915), Da tribuna e da imprensa (1915), Do retiro saudoso (1915), Pour l'Humanité (1916), Mansão dos amigos (conto, 1918), O habitat e a integridade nacional (These ao $6^{\circ}$ Congresso de Geographia em Bello Horizonte, 1920) e Livro de Alyr (1920) (DENIPOTI, 2001, p. 90).

Dario Vellozo era também adepto da maçonaria, assim como muitos dos intelectuais curitibanos desse período (MYSKIW, 2008), e defensor de ideias "neopitagóricas". Foi um dos membros fundadores do Instituto Histórico e Geográfico Paranaense, em 1900, e fundou, em 1909, o Instituto Neo-Pitagórico ${ }^{6}$. Nesse instituto, além de reuniões para discussões de obras, eram promovidas festas ao estilo dos cultos helênicos (ANDRADE, 2002). Porém, o destaque do INP ficava a cargo de sua editora, que estimulava a publicação e divulgação de obras. Dario Vellozo atuava como editor, sendo que vários livros e revistas simbolistas e anticlericais foram produzidos naquele espaço.

No que diz respeito ao ensino, Vellozo também possuía, para o quadro em pauta, um olhar diferenciado. Foi professor no Ginásio Paranaense a partir de 1899, além de

\footnotetext{
${ }^{6}$ O INP funciona até hoje. Nesse instituto são organizadas reuniões, palestras, cursos e oficinas abertas ao público sobre diversos temas como filosofia, história das religiões e ocultismo, entre outros. Além disso, a instituição possui uma biblioteca com vários livros publicados por sua editora no período que aqui nos interessa. O INP possui um site com mais informações: http://www.pitagorico.org.br/. Acesso em: 16 de julho de 2009.
} 
colaborador, redator ou editor de revistas voltadas para o ensino, como A Escola (órgão do grêmio dos professores; 1906-1910), Pátria e Lar (1912-1913) e Brazil Cívico (1918-1919).

Sua atuação editorial teve visibilidade maior, principalmente devido à sua fama e respeito, adquiridos em seu trabalho como professor. No papel de educador, ele pôde demonstrar sua vasta erudição:

\begin{abstract}
[...] formando em seus alunos verdadeiros discípulos que se constituiriam, com o grupo dos "novos", em continuadores das preocupações literárias do grupo do Cenáculo. Foi no periódico fundado por esses seus alunos, o Fanal, que essa admiração ficou expressa, tanto na deferência com que se referiam a Dario, como nas afirmações de que ele os inspirava (DENIPOTI, 2001, p. 80).
\end{abstract}

Sendo assim, suas preocupações pedagógicas, “[...] aliadas às suas preocupações com a formação teórica e prática do cidadão, além de seu perfil intelectual” (DENIPOTI, 2001, p. 80), culminaram na fundação da Escola Brazil Civico, na cidade de Rio Negro, ao sul de Curitiba, em 1913. A escola trazia, além das disciplinas teóricas curriculares, cursos profissionalizantes de agricultura, comércio, artes e indústria (DENIPOTI, 2001). Devido aos conflitos entre o Exército e os revoltosos do movimento do Contestado, a escola foi obrigada a se transferir para Curitiba. Porém, não durou muito tempo e antes de completar um ano foi fechada.

No que se refere à concepção de escola de Dario Vellozo, segundo Maria Lucia de Andrade (2007, p. 192), para ele a "escola moderna [...] deveria ser antes de tudo laica, pública, profissionalizante e obrigatória”.

Dario Vellozo ainda escreveu dois livros didáticos que foram muito utilizados pelas escolas curitibanas: Licções de História (1902) e Compêndio de Pedagogia (1907).

Devido ao seu grande reconhecimento como professor, as obras de Dario Vellozo supracitadas tiveram repercussão após suas publicações. Compêndio de Pedagogia teve grande receptividade no cenário educacional paranaense: "Os livros didáticos de Dario Vellozo contavam com um público cativo entre os professores de todo o país. Mesmo antes de sua publicação, já se criava uma grande expectativa em torno do Compêndio de Pedagogia ${ }^{7}$ (DENIPOTI, 2001, p. 82). Devido a todo esse prestigio no cenário intelectual, sua obra foi considerada como um "livro utilíssimo para o estudo nas Escolas normais do Brazil e para a

\footnotetext{
${ }^{7}$ Segundo Cristiane Vitório de Souza, em dissertação sobre as leituras pedagógicas de Silvio Romero, Romero possuía uma biblioteca específica de livros sobre educação e, entre eles, existe um exemplar da primeira edição do livro Compêndio de Pedagogia, de Vellozo. Para mais informações, ver: SOUZA, Cristiane Vitório de. As leituras pedagógicas de Silvio Romero. 2006. Dissertação (Mestrado em Educação) - UFSE (Universidade Federal de Sergipe), São Cristóvão, 2006.
} 
leitura constante daqueles que exercem a profissão nobilíssima do magistério" (MACEDO apud DENIPOTI, 2001, p. 82).

Segundo Denipoti, tanto Licções de História quanto o Compêndio de Pedagogia foram amplamente adotados por diversos professores do Ginásio Paranaense e da Escola Normal para o ensino. Myskiw ainda salienta que essas obras “[...] estão entre os livros reeditados e que lhe atribuíram certo reconhecimento na área de educação e história [...]" (MYSKIW, 2008, p. 8). Podemos dizer que essas duas obras marcam a face didática do professor Dario Vellozo.

O livro Licções de História teve sua primeira edição em 1902, a segunda em 1904 e a terceira em 1919, sendo ainda reeditado mais quatro vezes nos anos de 1943, 1944, 1948 e 1949, respectivamente (DENIPOTI, 2001). Tal livro é uma sucessão de apontamentos, em forma de lições e pequenos resumos, sobre a história da humanidade, partindo da pré-história e seguindo até a História Moderna. Esse livro é fruto do trabalho de Vellozo ao longo de anos como professor de História Universal em Curitiba.

Vellozo se aposenta do cargo de professor em 1930, porém, continua escrevendo textos e livros até seus últimos dias. Em 1933, escreve Atlântida, seu último livro, continua escrevendo outros textos menores e liderando as reuniões no INP. Em 1937, escreve o que seria seu último texto, Jesus Pitagórico, já com a saúde debilitada, e falece em 28 de setembro daquele ano.

Lançaremos um olhar mais apurado sobre a obra Compêndio de Pedagogia, nossa principal fonte e objeto desta pesquisa. O "compêndio" teve sua primeira publicação em 1907 e é um manual para o curso de Pedagogia da Escola Normal. A obra foi dividida em três anos: o primeiro ano aborda a trajetória histórica da Pedagogia, o segundo abarca aspectos teóricometodológicos e o terceiro é sobre a "pedagogia aplicada" (VELLOZO, 1975, p. 392), ou seja, a obra expõe um sistema específico para cada disciplina do curso primário.

Para a melhor compreensão da obra, Compêndio de Pedagogia, faremos uma análise da relação entre a obra e o contexto no qual ela foi concebida. Para tanto, utilizaremos, como proposta de abordagem, a História Intelectual, mais especificamente a proposta francesa de investigação histórica das ideias e de seus produtores, os intelectuais.

A História Intelectual se constitui em um ramo da história que ainda não possui delimitações muito precisas, entretanto, conta com marcos e trajetórias importantes definidas por alguns historiadores. Sendo assim, é importante apresentar algumas concepções teóricas referentes a essa abordagem. 
Comecemos por destacar a existência de, pelo menos, duas abordagens ou duas formas de fazer História Intelectual: a intellectual history e a histoire intellectuelle. A primeira diz respeito a uma abordagem feita principalmente pelos estadunidenses, voltada mais para as preocupações linguísticas e literárias de uma obra (CHARTIER, 2001). A segunda, com a qual dialogamos, surgiu na historiografia francesa e tem como seu principal foco "[...] o posicionamento das ideias, situando-as em seu contexto (intelectual e histórico) de produção" (SILVA, 2002, p. 12). Nesse sentido, essa abordagem busca fazer uma análise visando a uma articulação entre os elementos internos e os externos da obra. Assim, “[...] a história intelectual deve privilegiar a leitura de um texto em relação ao seu contexto. Isso significa considerar a obra em relação à formação social e cultural de seu autor, ao espaço ou 'campo' de produção e à conjuntura histórica dessa última” (SILVA, 2002, p. 12).

Nesse ponto, é importante destacar um conceito expresso nas linhas escritas pela historiadora Helenice Rodrigues da Silva. O conceito de "campo" por ela utilizado é estruturado a partir do pensamento do sociólogo francês Pierre Bourdieu. A historiadora acredita que o conceito de "campo" de Bourdieu pode ser aplicado a realidades vastas, como, por exemplo, a um campo cultural (campo artístico, literário) ou a um grupo de proporções menores (o campo editorial, uma revista ou a um grupo de intelectuais reunidos em institutos e clubes). Assim, essa concepção de campo proposta por Bourdieu se constitui em um espaço social, podendo ser entendido como uma rede de relações diretas e indiretas de posição (SILVA, 2002).

Essa concepção de "rede" supracitada aproxima-se do pensamento proposto pelo historiador francês Jean-François Sirinelli, que acredita que o termo "rede" deve ser utilizado para definir os locais em que os pensamentos e "laços se atam, por exemplo, em torno da redação de uma revista ou do conselho editorial de uma editora" (SIRINELLI, 1996, p. 248).

Acreditamos que a proposta de pesquisa delineada pela História Intelectual francesa deve ser fomentada em analisar as obras, levando em consideração seu texto e o seu contexto de produção, como bem apontou Carlos Eduardo Vieira:

De forma similar a história intelectual investe na análise dos processos de produção, circulação e recepção das ideias e dos discursos científicos, políticos, pedagógicos ou artísticos, desenclausurando-os da lógica e do método internalista da tradicional história das ideias (VIEIRA, 2008, p.80).

Assim, acreditamos que essa metodologia pode colaborar para a ampliação dos elementos que permitam a melhor compreensão das ideias e das obras de Dario Vellozo. 
No que diz respeito ao intelectual, vários autores se propuseram a discutir o papel desses agentes na sociedade e alguns traços que possam qualificar um indivíduo como tal. Carlos Eduardo Vieira nos apresenta quatro aspectos que, segundo ele, são fundamentais para concebermos os intelectuais como agentes sociais que possuem certa visibilidade na esfera cultural e atuam no campo político (VIEIRA, 2010). Os aspectos são apresentados da seguinte forma:

1) sentimento de pertencimento ao estrato social que, ao longo do século dezenove e vinte, produziu a identidade social do intelectual; 2) engajamento político propiciado pelo sentimento de missão ou de dever social; 3) elaboração e veiculação do discurso que estabelece a relação entre educação e modernidade; 4) assunção da centralidade do Estado como agente político para a efetivação do projeto moderno de reforma social. (VIEIRA, 2010, não publicado) ${ }^{8}$.

Partindo desse pressuposto traçado pelo autor, identificamos que Dario Vellozo, objeto de nossa pesquisa, pode ser relacionado com as dimensões descritas acima. Longe de pensarmos em uma definição forçada e engessada, essas ideias de atuações e vinculações dos intelectuais propostas por Vieira nos levam a enxergar as diversas possibilidades de atuações desses agentes sociais.

Passamos agora a discutir um pouco a questão do manual produzido com finalidade didática. Esse artefato da cultura escolar, apesar de ser de fácil identificação e de, em geral, as distinções entre esse tipo de publicação e outros livros serem dadas ou apresentadas sem grandes reflexões, a obra de cunho didático se constitui em um objeto de difícil definição (BITTENCOURT, 2008). Segundo Bittencourt: "é um objeto de múltiplas facetas, e para a sua elaboração e uso existem muitas interferências" (BITTENCOURT, 2008, p. 301).

Objeto material de grande importância no processo de construção de uma cultura escolar e de uma tecnologia de gestão da sala de aula e do coletivo de alunos, em que as noções de ordem e de método assumem uma enorme centralidade, os manuais didáticos foram, simultaneamente, instrumentos de inovação e de controle, pois atribuíam legitimidade a um conjunto de ideias e de práticas (e retirarem a outros), ao mesmo tempo em que apelavam à socialização e afirmação profissional dos futuros professores, com base num conjunto em que se articulavam o saber, o saber-fazer e o saber-ser. (CARVALHO, 2007)

Entendemos que os livros didáticos “[...] não são apenas instrumentos pedagógicos: são também produtos de grupos sociais que procuram, por intermédio deles, perpetuar suas identidades, seus valores, suas tradições, suas culturas" (CHOPPIN apud BITTENCOURT,

\footnotetext{
8 VIEIRA, Carlos Eduardo. Erasmo Pilotto: identidade, engajamento político e crenças dos intelectuais vinculados ao campo educacional no Brasil. Curitiba, 2010. Não publicado.
} 
2004, p. 69). Logo, os manuais didáticos podem nos revelar um pouco mais sobre a atmosfera educacional da qual esse livro foi concebido, além de serem compreendidos como “[...] estratégias de introdução de inovações das práticas pedagógicas e como exemplares da circulação e apropriação de ideias" (VALDEMARIN, 2007, p. 316). Nesse sentido, olharemos para o livro de Vellozo, tendo em mente essas questões expostas acima.

Enfim, trata-se de compreender o manual escolar de Vellozo, como espaço de divulgação e propagação de ideias e propostas políticas e, nesse sentido, de conquista "de corações e mentes". Formador, transformador e "alimentador" do imaginário republicano em Curitiba, no Paraná e no Brasil, é possível tomá-lo como objeto de investigação historiográfica e, deste ponto em diante, passamos a discorrer sobre o livro de Vellozo.

Começamos por destacar que a primeira edição da obra Compêndio de Pedagogia, em 1907, foi subsidiada pelo governo do Paraná e se tornou de uso obrigatório nas Escolas Normais do estado. Isso nos mostra que Vellozo comungava, pelo menos em algumas questões educacionais, com as preocupações e ideias as quais o governo estadual estava interessado em propagar nesse período e que, em contrapartida, fazia com que enxergasse no autor e em suas obras instrumentos de divulgação e formação de ideias e de motivação de ações.

No que tange a elementos textuais da obra, o livro é dividido em três partes que correspondem aos três anos dos cursos normais. O primeiro ano é composto por dez lições e começa com uma definição de Pedagogia; em seguida, apresenta-se uma trajetória histórica da educação, começando pela educação na Antiguidade, passando pelos povos chineses, egípcios, pelo período medieval e terminando no que Dario Vellozo chama de tempos modernos.

A segunda parte do livro (o segundo ano), para a qual dedicaremos um olhar mais cuidadoso, também é formada por dez lições, tendo início com uma descrição dos métodos de ensino indutivo e dedutivo, passando por princípios didáticos, modos, formas e processos de ensino. As últimas lições dessa parte serão tomadas como os principais objetos de análise e reflexão, pois são as que melhor representam a tentativa de formar alunos/professores condizentes com os ideais republicanos. Essas lições estão divididas em Educação Física, Intelectual, Moral, Estética e, por fim, a Educação Cívica, cada uma com algumas ramificações que serão discutidas e apresentadas mais adiante.

A última divisão da obra (o terceiro ano) abarca 11 lições, que se iniciam com uma abordagem sobre a iniciação à leitura e à escrita, passando por estudos da língua portuguesa, 
bem como estudos de geografia, de história, de ciências, de desenho, de música, de canto, além de instruções morais e cívicas que o professor deveria ensinar para o aluno. Essa divisão era utilizada principalmente para instruir os professores sobre questões básicas das disciplinas descritas acima.

Assim, começamos a discutir a noção de pedagogia apresentada por Dario Vellozo. Segundo o autor, a "[...] pedagogia é a arte e a ciência da educação (VELLOZO, 1975, p. 395). Aqui percebemos que Vellozo transita em um campo que estava longe de ser um ponto pacífico entre os teóricos da educação do período, ou seja, conceituar a pedagogia e apresentar uma resposta final a uma pergunta que definiria esse campo do conhecimento: a pedagogia é uma arte, uma ciência ou arte e ciência concomitantemente? Para entendermos melhor essa questão, precisamos compreender como estava sendo entendida a pedagogia como arte e como ciência, no período e por Dario Vellozo.

A pedagogia enquanto arte pode ser entendida como “[...] um acúmulo de habilidade prática que supõe um conhecimento além dos adquiridos nos livros, ou seja, remete para a dimensão prática e aplicada da educação baseada na observação e aplicação dos conhecimentos adquiridos ao longo do tempo" (FRANCO, 2008, p. 27). Nesse sentido, a pedagogia como arte da educação era baseada em experiências e vivências da sala de aula e não contava com um estudo mais teórico sobre a forma como ocorria o ensino. Focava um conhecimento adquirido através da prática.

Por seu turno, a pedagogia como ciência se tornou mais forte no século XIX, com base em todo o contexto de crença na ciência que se constituiu nesse período. Nesse sentido, para ganhar o status de científica, a pedagogia precisou adequar-se à lógica que presidia a ciência da época e isso implicou em sistematizar suas ações práticas, com base nas teorizações dos experimentos possíveis ao momento histórico. Assim, a pedagogia científica acaba “[...] renovando seu método e seu conteúdo pela adoção do paradigma científico, indutivo e experimental, articulando em conhecimentos baseados em fatos" (CAMBI, 1999, p. 498).

Dessa maneira, o paradigma científico passa a dar um caráter mais teórico à pedagogia, haja vista que a arte da pedagogia era baseada muito mais em questões práticas do que em um estudo mais profundo sobre o método do ensino. Porém, a pedagogia como arte e a pedagogia como ciência não são excludentes. Pelo contrario, a ciência deveria auxiliar por meio de suas regras e leis, e atualizar os métodos da arte de ensinar, ou seja, da prática do ensino.

Assim, com seus métodos, leis e regras, a ciência prestaria auxílio à prática do ensino, tentando torná-lo mais eficaz por estar baseado nos métodos modernos da ciência. 
Nesse mesmo sentido exposto acima, Vellozo afirma que foi através de um “[...] conjunto de tentativas, dessa respeitável soma de experiências, cujos resultados têm sido apreciados através de milênios, que formou-se a arte pedagógica, a arte da educação" (VELLOZO, 1975, p. 396). Ou seja, a arte da educação é a forma de ensino adquirida por várias gerações através da prática. E, a partir de “[...] seus métodos, modos, formas e processos, formou-se a ciência pedagógica, a ciência da educação, com suas regras, princípios e leis".

Contudo, não houve uma convivência muito harmônica entre essas duas concepções de pedagogia. O próprio Vellozo cita em seu livro essa divergência, apontando alguns autores que defendiam a ideia da pedagogia ser apenas arte, enquanto outros, apenas ciência, e alguns defendendo a pedagogia como arte e ciência. O próprio relator do parecer já citado, Francisco Azevedo Macedo, defendia que a pedagogia era uma arte. Essa discussão esteve longe de acabar no início do século XX, basta como exemplo o texto de Anísio Teixeira de 1957, que traz uma discussão sobre a educação como uma arte e ciência. Nesse sentido, esse autor afirma que a ciência da educação deveria:

\footnotetext{
[...] dar condições científicas à atividade educacional, nos seus três aspectos fundamentais - de seleção de material para o currículo, de métodos de ensino e disciplina, e de organização e administração das escolas. Por outras palavras: trata-se de levar a educação para o campo das grandes artes já científicas - como a engenharia e a medicina - e de dar aos seus métodos, processos e materiais a segurança inteligente, a eficácia controlada e a capacidade de progresso, já asseguradas às suas predecessoras relativamente menos complexas (TEIXEIRA, 1957, p. 12).
}

Uma característica importante do compêndio de Vellozo é mostrar algumas divergências existentes em relação a determinada temática e posicionando-se diante da discussão. Um exemplo dessa característica é a discussão feita sobre a noção de pedagogia que discutimos. Outro exemplo dessa forma de escrita está presente na discussão elaborada por Vellozo a respeito dos modos de ensino. Segundo o autor, os modos de ensino são a maneira com que são organizados os alunos na escola para que haja um melhor aproveitamento do ensino.

Assim, Vellozo apresenta o modo individual, no qual o professor leciona para um aluno de cada vez; o modo simultâneo, que é caracterizado pela divisão dos alunos em classe, com base em seus níveis de conhecimento; o modo mútuo, que se assemelha ao modo simultâneo, mas possui como diferença a utilização de alunos mais avançados como monitores para auxiliar o professor; e o modo misto, que é a possível combinação dos outros modos. Após descrever esses modos, o autor afirma que o modo simultâneo "[...] é o mais 
adotado, de incontestável vantagem, talvez o único que, dada a atual organização escolar, possa aproveitar o ensino" (VELLOZO, 1975, p. 433).

Entendemos que essa característica de escrita de Vellozo, de apresentar alguns pontos de vista em determinados momentos e de se posicionar sempre a favor do que ele considera mais atual ou mais utilizado, nos revela duas questões importantes. A primeira mostra o seu conhecimento amplo e domínio do tema que está tratando, mostrando uma preocupação em apresentar um estudo com densidade teórica mais consistente e não apenas um apanhado de ideias.

Outra questão que gostaríamos de levantar diz respeito à preocupação de Vellozo em apresentar autores e correntes de pensamento que estavam em voga no pensamento pedagógico da época. Autores como Pestalozzi, Spencer, Bain, Compayrè e Fröebel, que gozavam de um grande prestígio entre os teóricos da educação do final do século XIX e início do século XX (CAMBI, 1999), são citados por Vellozo como referências de novas propostas de ensino. O método de ensino intuitivo, que foi uma das grandes apostas de renovação do ensino no século XIX e XX, também é citado por ele como uma nova proposta educacional.

Dessa forma, Vellozo procurou estar em sintonia com as discussões educacionais que estavam ocorrendo em âmbito mundial, atentando para sua preocupação de ser moderno e estar atualizado sobre as principais transformações que estavam ocorrendo no cenário educacional. Entendendo que essa modernidade ${ }^{9}$ que esse autor buscava pode ser “[...] representada pela confiança na ação edificante da razão que, através da ciência, da tecnologia, da instrução e das políticas sociais universalizaram um novo modo de pensar e sentir a realidade" (VIEIRA, 2010).

A necessidade de ser moderno que Vellozo sentia está atrelada à noção de intelectual com a qual estamos trabalhando, ou seja, a preocupação de estabelecer uma relação entre a educação e a modernidade, apontando a educação como um caminho a ser trilhado para alcançar a meta, que seria a modernidade social. Característica essa que não era exclusividade de Vellozo, e sim de uma gama de agentes sociais do final do século XIX e início do século $\mathrm{XX}$.

A ideia de "educação integral" como uma perspectiva moderna de educação foi outro ponto defendido por Vellozo. Assim, ele acreditava que apenas a educação integral poderia preparar o cidadão para interagir com o mundo. Nesse sentido, o autor entendia que a

\footnotetext{
${ }^{9}$ Ver, entre outros, BERMAN, Marshall. Tudo que é sólido desmancha no ar. São Paulo: Companhia das Letras, 1986.
} 
educação integral dividia-se em física, intelectual, moral e estética, porém cita também a educação cívica, que perpassaria as outras formas de educação e teria como objetivo ensinar os direitos e deveres do cidadão. Assim, a educação física, intelectual, moral e estética propiciariam ao cidadão cumprir suas atuações cívicas.

Vellozo entendia que a educação era um: “[...] conjunto de ponderados esforços no sentido de desenvolver as faculdades físicas, intelectuais e morais do indivíduo, facultandolhe meios de aperfeiçoamento, para felicidade própria e alheia" (VELLOZO, 1975, p. 397). Assim, entendia que a educação deveria ocorrer em diversos âmbitos, pois o cidadão pleno deveria ser bem instruído, possuir aptidões físicas e zelar pelo convívio, buscando uma sociedade harmônica. Vale lembrar que a ideia de formação do indivíduo apto para atuar na sociedade era a premissa central da educação para Vellozo.

A ideia de educação integral apresentada por esse autor fazia parte de um esforço de reorganização da educação brasileira que ocorreu no final do século XIX e início do século XX. Essa reorganização buscou renovar o método de ensino, bem como ampliar o programa escolar. A base dessa ampliação seria calcada no princípio da educação integral, que englobaria a educação física, intelectual e moral (SOUZA, 2000). Percebemos que Vellozo estava em sintonia com as mudanças educacionais que estavam ocorrendo no cenário nacional, na medida em que, em seu livro, ele defende algumas das ideias de renovação do ensino, como o método intuitivo e a perspectiva de educação integral, que estavam sendo propostas por alguns pensadores da educação, como, por exemplo, Rui Barbosa.

A prerrogativa de educação integral, formada pela tríade educação física, intelectual e moral, foi formulada e difundida a partir da obra de Herbert Spencer, intitulada: "Educação Intelectual, Moral e Física", e publicada em 1861. Essa obra buscava unir uma concepção de educação com as aspirações e necessidades da sociedade moderna. O apelo de Spencer à correspondência entre a lei da evolução biológica e o progresso social possibilitou a naturalização da evolução da sociedade e a compreensão da ciência como o conhecimento mais relevante, o conhecimento útil com aplicação no trabalho, na arte e na vida diária.

Nessa concepção, corpo e espírito são indissociáveis. O princípio da educação integral expressava essa compreensão unificada pela qual a educação seguia as leis da natureza e a ciência revelava-se como o melhor meio para a disciplina intelectual e a disciplina moral (SPENCER, 1901). Da mesma forma, Vellozo acreditava que apenas a ciência poderia mostrar um real conhecimento, visto que, em diversos momentos, defendeu a importância da ciência na educação. Além dessas proximidades, Vellozo cita o livro de Spencer como uma 
das referências suas utilizadas para escrever o compêndio e recomenda-o para ser lido pelos professores.

A inserção do pensamento de Spencer na educação brasileira não se faz apenas por essa discussão de Vellozo, haja vista que Rui Barbosa, em seu parecer acerca da "Reforma do ensino primário e várias instituições complementares da instrução pública”, publicado em 1883, compartilhava das ideias de Spencer e as recomendava à educação pública brasileira (SOUZA, 2000).

Nesse sentido, o primeiro ponto abordado por Vellozo é a Educação Física. Segundo o autor do "compêndio", ela é importante na medida em que auxilia o aluno a se tornar um indivíduo "robusto" e "sadio". Vellozo ainda argumenta que, para que o aluno possua uma boa compreensão do que lhe está sendo ensinado, necessita de um físico forte, pois: "sem robustez, sem saúde o corpo é débil, fraca a memória, a compreensão mais difícil" (VELLOZO, 1975, p. 438).

A Educação Física, segundo Vellozo, possui dois elementos principais: a ginástica e a higiene. Para o pensador, a ginástica tem por finalidade fortalecer os músculos e aumentar a força do aluno. Já a higiene possui por finalidade eliminar "maus hábitos" e melhorar a saúde do aluno e a qualidade do ambiente escolar. Assim, a educação física possibilitaria a constituição de corpos saudáveis, fortes e vigorosos, auxiliaria a disciplinar os hábitos e costumes responsáveis pelo cultivo dos valores cívicos e patrióticos. De acordo com Soares (1994), a educação física das crianças no Brasil emerge atuando na preparação do corpo feminino para a reprodução dos filhos da pátria e na preparação do corpo do soldado tornando-o útil à pátria e ao capital, além de vincular algumas questões de moral, saúde e produtividade do trabalho a essa educação. Para Vellozo, o futuro cidadão deveria possuir uma saúde e vigor físicos apurados para bem servir à pátria e à família, que foram duas preocupações do autor em estudo.

O segundo ponto destacado por Vellozo é a Educação Intelectual. De acordo com ele: "a educação intelectual é o sistema que trata de desenvolver, elucidar, enriquecer e orientar a mente" (VELLOZO, 1975, p. 440). Destaca-se a explicação que Vellozo elabora para justificar a Educação Intelectual: “a educação intelectual proporciona o saber, o conhecimento exato das coisas, a consciência e a verdade, pela ciência" (VELLOZO, 1975, p. 441). Ele estava encantado com a ciência, encanto esse que atingiu vários pensadores do século XIX, período que foi marcado por uma grande adesão às ideias científicas. Novamente evocamos a figura de Spencer para elucidar a fonte com a qual Vellozo dialoga. Spencer teceu questões 
importantes para entendermos a concepção moderna do papel social da ciência na sociedade e na educação ao apontá-la como o conhecimento de maior valor:

\begin{abstract}
Assim, para a pergunta que formulamos - quais são os conhecimentos de maior valor? - há uma resposta uniforme - a Ciência. É o veredicto para todas as interrogações. Para a direta conservação própria, para a conservação da vida e da saúde, o conhecimento mais importante é a Ciência. Para a indireta conservação própria, o que se chama ganhar a vida, o conhecimento de maior valor é a Ciência. Para o justo desempenho das funções da família, o guia mais próprio só se encontra na Ciência. Para a interpretação da vida nacional, no passado e no presente, sem o qual o cidadão não pode justamente regularizar o seu procedimento, a chave indispensável é a Ciência. Para a produção mais perfeita e para os gozos da arte em todas as suas formas, a preparação imprescindível é ainda a Ciência, e para os fins da disciplina intelectual, moral e religiosa - o estudo mais eficaz é, ainda, uma vez, a Ciência (SPENCER, 1901, p. 73).
\end{abstract}

Para esse autor a ciência era o conhecimento que melhor revelava o sentido do progresso e da sociedade dita civilizada do, século XIX. Para tanto, a ciência sobressaía como um conhecimento essencial para a vida moderna, o conhecimento útil e válido cujas verdades podiam ser aplicadas aos mais variados negócios da vida prática: na indústria, no trabalho, na conservação da saúde, no exercício dos deveres políticos e sociais, na condução da vida moral. Vellozo foi um adepto dessa fé na ciência, e em seu livro podemos perceber a importância que ele atribui à ciência empírica, defendendo que apenas essa ciência pode levar ao conhecimento verdadeiro da sociedade.

A próxima questão abordada por Vellozo é a Educação Moral. Ele acreditava que as faculdades morais formariam o caráter do aluno. Assim, a Educação Moral tinha por objetivo “[...] desenvolver e formar a vontade, estabelecendo normas de conduta, ensinando os deveres e as virtudes, para o Bem" (VELLOZO, 1975, p. 441).

Vellozo ainda defendia que o caráter da criança deveria ser desenvolvido por uma prática de ensino pautada na verdade científica, pois, para ele, o "saber leva à verdade; a educação intelectual contribui para a educação moral, dando ao indivíduo o máximo grau possível de consciência pelo conhecimento exato das coisas" (VELLOZO, 1975, p. 443). Dessa forma, notamos em Vellozo a crença no princípio segundo o qual quanto maior for o conhecimento fomentado pela verdade científica, melhor será o caráter do indivíduo.

A concepção de educação moral de alguns republicanos mais radicais no período da primeira República brasileira - caso de Dario Vellozo - colocou em evidência a secularização da moral de natureza cívica em detrimento à moral religiosa. Nesse sentido, convinha, pois, desenvolver sentimentos e hábitos, cultivar valores morais desejáveis, tais como: respeito à ordem, disciplina, tolerância, amor ao dever, apreço ao trabalho, o bom emprego do tempo, a sinceridade, a lealdade e o amor à pátria. 
A separação entre o Estado e a Igreja foi a motivação dessa mudança de moral, que passou a ser voltada ao culto da nação. Vale lembrar que a transformação não se deu de maneira abrupta e nem por completa, haja vista que muitas práticas religiosas ainda continuaram a ser realizadas após essa separação. Nesse sentido, Vellozo acreditava que a moral deveria fazer com que o aluno soubesse respeitar o próximo para que houvesse uma melhor convivência e, assim, o país conseguiria uma união melhor para alcançar o progresso. Portanto, a ideia de respeito e união não estava atrelada a uma visão religiosa, e sim pautada em uma perspectiva e união para o desenvolvimento econômico e social do país.

Concomitantemente com a educação moral está a educação estética para Dario Vellozo. Segundo o autor, "a educação estética desenvolve os sentimentos superiores, não só é fonte de emoções supremas, como fator da educação moral" (VELLOZO, 1975, p. 443).

Essa educação era dividida, para ele, em belas letras - que englobava a literatura - e belas artes - compostas por esculturas, pinturas, arquitetura, música e canto. Vellozo ainda atentava para o ensino do senso crítico da arte.

A questão da educação estética se fazia presente em discussões de alguns teóricos educacionais - como Spencer, Froebel e Pestalozzi - como uma importante faceta da educação. Vale lembrar ainda que Schiller, em suas cartas, foi categórico ao defender que não é possível elevar moralmente e racionalmente o ser humano sem cultivar a sua emoção e sensibilidade, sendo possível apenas o desenvolvimento completo do homem a partir de um equilíbrio entre a razão e a emoção (SCHILLER, 1995).

Aproximando essa discussão para o cenário republicano brasileiro, a educação estética ganhou um componente a mais: o caráter de cívico, ou seja, foi utilizada, algumas vezes, como forma de auxiliar o ensino cívico. Assim, “[...] o despertar para a civilidade não se faria apenas com a abertura de escolas, mas com uma educação estética que envolvesse habilidades manuais, educação das mulheres para o lar, o contato com a literatura brasileira, os cantos, a dança [...]" (VEIGA, 2003, p. 406).

Além dessas questões que estavam em voga no período, Vellozo ainda possuía um apego a mais à educação estética: sua própria veia artística, motivo pelo qual ganhou notoriedade no cenário curitibano como poeta e produziu literatura até a sua morte. Tinha familiaridade com a música, pois tocava instrumentos de sopro, além de ter pintado algumas telas. Seu amor pelas artes faz com que ele acrescente uma importância a mais a essa educação, pois, segundo entendia: "os mais delicados prazeres da vida são propiciados pela arte" (VELLOZO, 1975, p. 443). Isso além de entender que "pedagogicamente a arte e a 
moral são inseparáveis" (VELLOZO, 1975, p. 444). Assim, uma boa educação estética pode ajudar a ter uma boa educação moral.

Por fim, Vellozo discute a educação cívica. O pensador defendia que todas as outras "educações" deveriam trabalhar juntas para que fosse formada esta. De acordo com ele: "a função principal da escola é formar futuros cidadãos, aptos e conscientes" (VELLOZO, 1975, p. 444). Nesse sentido, a educação cívica teria por finalidade ensinar os deveres e os direitos do cidadão, estabelecidos em relação à sociedade e à pátria.

Para Dario Vellozo, a educação cívica seria o fim a ser alcançado pela educação, pois, segundo ele, "educados física, intelectual, moral e esteticamente, o homem e a mulher ficam em condições de bem servir à família, à pátria e à humanidade - que tal é o fim da educação cívica" (VELLOZO, 1975, p. 444). Assim, percebemos que a educação possuía uma missão específica no pensamento de Vellozo: a formação de pessoas para servir à pátria e família para que o país pudesse alcançar o seu progresso pleno, tanto na área econômica, quanto na social.

Após a leitura e análise da obra "Compêndio de Pedagogia", podemos perceber que o sentido de servir à pátria se apresenta em consonância com o discurso republicano em voga no Brasil do final do século XIX e início do século XX, tanto em âmbito nacional, como em âmbito estadual. Nota-se assim, novamente, que Vellozo era adepto do discurso republicano. Dessa forma, apresentados os elementos fundamentais da educação humana, o indivíduo seria também um homem político mais capaz. Nesse mesmo sentido, percebemos a educação integral como um dos fatores essenciais na formação humana, pois, para alcançar um progresso, uma evolução social nos quais Vellozo acreditava, o homem deveria ser educado em seus diversos sentidos. Percebemos novamente relações entre Vellozo e Spencer, no sentido da crença em uma evolução humana, tendo como base a ciência.

À guisa de conclusão, nossa análise procurou discutir alguns aspectos do pensamento pedagógico de Dario Vellozo manifestados em sua obra Compêndio de Pedagogia. Seu manual didático, além de indicar aspectos muito significativos de seu pensamento pedagógico, mostra-nos uma possível tendência que pairava sobre o cenário da educação paranaense no período em apreço. A educação, para Vellozo, deveria construir um homem capaz de pensar politicamente de forma livre (leia-se: republicana) e apto a desenvolver a sociedade rumo à ordem e ao progresso. 


\section{Referências}

\section{1) Fontes}

VELlOZO, Dario. Compendio de Pedagogia. In: OBRAS IV: Curitiba: Instituto NeoPitagórico, 1975.

\section{2) Bibliografia}

ANDRADE, Maria Lucia. Educação, cultura e modernidade: o projeto formativo de Dario Vellozo. 2002. Dissertação (Mestrado em Educação) - Universidade Federal do Paraná, 2002.

Dario Vellozo e a escola moderna: a renovação do pensamento educacional no Paraná (1906-1918). In: VIEIRA, Carlos Eduardo (org.). Intelectuais, educação e modernidade no Paraná (1886-1964). Curitiba: UFPR, 2007.

BEGA, Maria Tarcisa Silva. Sonho e invenção no Paraná: geração simbolista e a construção de identidade regional. 2001. Tese (doutorado em Sociologia). Universidade de São Paulo, 2001 .

BERMAN, Marshall. Tudo que é sólido desmancha no ar. São Paulo: Companhia das Letras, 1986.

BITTENCOURT, Circe (org.). O saber histórico na sala de aula. 9. ed. São Paulo: Contexto, 2004.

Ensino de História: fundamentos e métodos. 2. ed. São Paulo: Cortez, 2008.

CAMBI, Franco. História da Pedagogia. São Paulo: UNESP, 1999.

CAMPOS, Nevio de. Laicato católico: o papel dos intelectuais no processo de organização do projeto formativo da Igreja Católica no Paraná (1926-1938). 2002. Dissertação (Mestrado em Educação) - Universidade Federal do Paraná (UFPR), Curitiba, 2002.

CARVALHO, José Murilo de. A formação das almas: imaginário da república no Brasil. São Paulo: Companhia das Letras, 1990.

Os bestializados: o Rio de Janeiro e a república que não foi. São Paulo: Companhia das Letras, 1987.

A Nova Historiografia e o Imaginário da República. Revista anos 90, Revista de Pós-Graduação em História, Porto Alegre, v. 1, n. 1, p. 11-21, maio de 1993.

CARVALHO, Marta Maria Chagas de. Uma biblioteca pedagógica francesa para a Escola Normal de São Paulo (1882): livros de formação profissional e circulação de modelos culturais. In: BENCOSTTA, Marcus Levy (org). Culturas escolares, saberes e práticas educativas: itinerários históricos. São Paulo, Cortez, 2007. 
CHARTIER, Roger. À beira da falésia: a história entre certezas e inquietude. Porto Alegre, EDUFRGS, 2001.

CORRÊA, Amélia Siegel. Imprensa e política no Paraná: prosopografia dos redatores e pensamento republicano no final do século XIX. 2006. Dissertação (Mestrado em Sociologia) - Universidade Federal do Paraná, Curitiba, 2006.

DENIPOTI, Cláudio. Um homem no mundo do livro e da leitura. Revista de História Regional (UEPG), Ponta Grossa, ano 6, v. 2, p. 75-91, 2001.

D'ONOFRIO, Salvatore. Literatura ocidental. Autores e obras fundamentais. 2. ed. São Paulo: Ática, 2002.

FRANCO, Maria Amélia do Rosário Santoro. A pedagogia como ciência da educação. 2. ed. ver. ampl. São Paulo: Cortez, 2008.

MARCHETTE, Tatiana Dantas. Corvo no galho das acácias: o movimento anticlerical em Curitiba (1896-1912). Curitiba: Aos Quatro Ventos, 1999.

MYSKIW, Antonio Marcos. Curitiba, "República das Letras" (1870-1920). Revista eletrônica Reflexões em História. Dourados, v. 2, n. 3, p. 1-27, 2008. Disponível em: $<$ http://www.historiaemreflexao.ufgd.edu.br/Curitiba_republica_das_letras.pdf $>$. Acesso em: 01 jun. 2008.

PRIORE, Mary del; VENANCIO, Renato Pinto. O livro de ouro da história do Brasil. Rio de Janeiro: Ediouro, 2001.

SCHILLER, Friedrich. A educação estética do homem. São Paulo: Iluminuras, 1995.

SILVA, Helenice Rodrigues da. Fragmentos da história intelectual: entre questionamentos e perspectivas. Campinas, Papirus, 2002.

SIRINELLI, Jean-François. Os Intelectuais. In: RÉMOND, René (org.). Por uma história política. Rio de Janeiro: UFRJ, 1996, p. 231-269.

SOARES, C.L. Educação física: Raízes européias e Brasil. Campinas: Autores Associados, 1994.

SOUZA, Cristiane Vitório de. As leituras pedagógicas de Silvio Romero. 2006. Dissertação (Mestrado em Educação) - Universidade Federal de Sergipe - (UFSE), São Cristóvão, 2006.

SOUZA, Rosa Fátima de. Inovação educacional no século XIX: A construção do currículo da escola primária no Brasil. Cadernos Cedes, Campinas, n. 51, novembro de 2000.

SPENCER, H. Educação: Intellectual, moral e physica. Porto: Casa Editora Alcino Aranha, 1884. 
TEDARDI, Vivian Noitel Valim. Pensamentos e leituras de Dario Vellozo sobre etnia brasileira. 2002. Monografia (Graduação em História) - Universidade Tuiuti do Paraná, Curitiba, 2002.

TRINDADE, Etelvina Maria de Castro; ANDREAZZA, Maria Luiza. Cultura e educação no Paraná. Curitiba: SEED, 2001.

VALENTE, Silza Maria Pazello. A presença rebelde na cidade sorriso: contribuição ao estudo anarquista em Curitiba (1890-1920). 1992. Dissertação (Mestrado em Educação) Universidade Estadual de Campinas (UNICAMP), Campinas, 1992.

VEIGA, Cynthia Greive. Educação estética para o povo. In: LOPES, Eliane Marta; MENDES, Luciano \& VEIGA, Cynthia, (Orgs.) 500 anos de educação no Brasil. Belo Horizonte: Autêntica, (2003).

VIEIRA, Carlos Eduardo. Intelligentsia e intelectuais: sentidos, conceitos e possibilidades para a história intelectual. Revista brasileira de história da educação. Campinas: Autores Associados, Janeiro/abril, n. 16, p. 63-85, 2008.

Erasmo Pilotto: identidade, engajamento político e crenças dos intelectuais vinculados ao campo educacional no Brasil. Curitiba, 2010. Não publicado. 